\title{
HIF-1-mediated expression of Foxo1 serves an important role in the proliferation and apoptosis of osteoblasts derived from children's iliac cancellous bone
}

\author{
GANG XU \\ Department of Orthopedics, The Children's Hospital, Zhejiang University School of Medicine, \\ Hangzhou, Zhejiang 310000, P.R. China
}

Received May 5, 2017; Accepted February 8, 2018

DOI: $10.3892 / \mathrm{mmr} .2018 .8675$

\begin{abstract}
Activation of the transcription factor hypoxia inducible factor- $1 \alpha(\mathrm{HIF}-1 \alpha)$ is considered critical for the stimulation of osteogenic markers including runt-related transcription factor 2 (Runx2), alkaline phosphatase (ALP) and osteocalcin, which are closely associated with forkhead boxclass $\mathrm{O} 1$ (Foxo1) levels in osteoblasts. The present study explored the associations between HIF-1 $\alpha$ and Foxol in the regulation of cell viability, proliferation and apoptosis of osteoblasts. Osteoblasts obtained from children's iliac cancellous bone were used in the present study, which were confirmed by immunofluorescence staining for the osteoblast marker osteocalcin. The results revealed that the levels of reactive oxygen species and apoptosis were markedly increased in cells with knockdown of HIF-1 $\alpha$. By contrast, these were reduced in response to overexpressed HIF-1 $\alpha$. In addition, HIF-1 $\alpha$ overexpression significantly stimulated cell viability, which was suppressed by silencing HIF-1 $\alpha$. HIF-1 $\alpha$ overexpression also significantly increased the transcriptional and translational levels of Foxo1. Conversely, silencing HIF-1 $\alpha$ markedly suppressed the expression levels of Foxo1. Furthermore, silencing HIF-1 $\alpha$ reduced the expression of osteogenic markers, including Runx2, ALP and osteocalcin. Runx 2 and ALP expression induced by HIF1 $\alpha$ were markedly reversed by Foxo1 small interfering (si)RNA, whereas osteocalcin was not significantly affected by Foxol siRNA. Therefore, the cooperation of and interactions between HIF-1 $\alpha$ and Foxol may be involved in the regulation of osteoblast markers, and serve a pivotal role in the proliferation and apoptosis of osteoblast. The HIF1 $\alpha$-induced expression of Runx 2 and ALP may be completely dependent
\end{abstract}

Correspondence to: Dr Gang Xu, Department of Orthopedics, The Children's Hospital, Zhejiang University School of Medicine, 3333 Banishing Road, Hangzhou, Zhejiang 310000, P.R. China E-mail: flyferrali@zju.edu.cn

Key words: hypoxia inducible factor-1 $\alpha$, osteoblast, forkhead box class O1, runt-related transcription factor 2, alkaline phosphatase, osteocalcin on the expression levels of Foxo1, and in turn, osteocalcin may be partially dependent on Foxol expression.

\section{Introduction}

Osteoporosis and fractures are the most common orthopedic diseases in the elderly (1). have been plagued by the delayed healing and nonunion of fractures, bone defects and osteoporosis have become a growing concern for orthopedic clinicians, and the outcome of current clinical treatments are not very satisfactory. Therefore, in order to prevent and reduce the occurrence of osteoporosis and fracture, understanding the mechanisms underlying osteoporosis and fracture healing has become important in research associated with bone injury.

The maintenance of the normal functional state of the body is dependent on an appropriate supply of oxygen. In addition, maintaining homeostasis in regard to oxygen levels is a prerequisite for cell life activity (2), and tissue oxygen concentrations must be precisely controlled to fluctuate only within a very small range $(2,3)$. Due to a reduction in blood supply following bone or soft tissue injury, the microenvironment surrounding lesions enters a hypoxia state (4). Thus, angiogenesis serves an important role in the process of fracture healing $(5,6)$. Osteogenesis is closely associated with angiogenesis in the formation and repair of bone (5-7). Vessels carry oxygen and nutrients; however, they also serve a pivotal role in the formation, reshaping and alteration of bone through interactions between osteoblasts, osteocytes or osteoclasts and cytokines in the blood vessels (5-7). Hypoxia is considered to be an important stimulus in angiogenesis (8); this stimulus is now thought to be achieved by hypoxia inducible factor- $1 \alpha$ $(\mathrm{HIF}-1 \alpha)(9)$. HIF-1 $\alpha$ is a key regulator of vertebrate adaptation to hypoxia (9). The study of HIF-1 $\alpha$ expression levels, its function and hypoxia status under physiological and pathological conditions in the skeletal system has become an area of growing interest $(10,11)$. There are two main aspects associated with the regulatory function of HIF-1 $\alpha$ in fracture healing. The first being that HIF-1 $\alpha$ can induce the formation of blood vessels during the healing process of the fracture by stimulating the expression of vascular endothelial growth factor (VEGF) (10,11). Secondly, HIF-1 $\alpha$ is directly involved with the regulation of cell functioning, including in osteoblasts, 
osteoclasts and chondrocytes $(10,11)$. However, the detailed mechanisms of HIF-1 $\alpha$ in the proliferation, apoptosis and differentiation of osteoblasts have not been fully elucidated. Previous studies have revealed that blocking expression of runt-related transcription factor 2 (Runx2) and HIF-1 $\alpha$ inhibited the formation of heterotopic ossification $(11,12)$. Runx2 can stabilize HIF-1 $\alpha$ structure via the inhibition of HIF-1 $\alpha$ ubiquitination in order to promote angiogenesis in growth plate hypertrophic chondrocytes (12).

Forkhead box class O1 (Foxo1) is one of the earliest members identified in the Foxo family, and is also the most representative of the Foxo family. Previous studies had demonstrated that they serve an important role in a number of physiological and pathological processes, including proliferation, apoptosis, phagocytosis, metabolism, inflammation, differentiation and oxidative stress $(13,14)$. Previous studies revealed that Foxo1 mediates dendritic cells and macrophages in order to regulate associated target genes in inflammatory responses (15); osteoclasts, dendritic cells and macrophages share a common precursor cell line. However, only Foxol is the transcription factor required for osteoblast proliferation and the maintenance of the body's redox balance (16). In addition, previous studies have demonstrated that interactions and cooperation between Foxoland Runx 2 serve a key role in the transcriptional regulation of osteoblast markers, including alkaline phosphatase (ALP), and osteocalcin (17,18). Runx2, ALP and osteocalcin are closely associated with the development of osteoblasts.

In addition, orthopedic diseases in children and adolescents, such as osteoporosis, and children with avascular necrosis and non-traumatic avascular necrosis of the femoral head, have received little attention when compared with orthopedic diseases observed in the elderly (19-21). A previous study revealed that the negative associations between HIF-1 $\alpha$ and the rate of bone cell apoptosis was involved in the non-traumatic avascular necrosis of the femoral head (22). Furthermore, there has been no report regarding the associations between HIF-1 $\alpha$ and Foxo1. Thus, in the present study, children's iliac cancellous bone was used to determine whether HIF-1 $\alpha$ regulates the proliferation, differentiation and apoptosis of osteoblasts through the regulation of Foxol expression.

\section{Materials and methods}

Cell culture. Bone tissues were obtained between February 2015 and March 2017 from children with congenital dislocation of the hip when they underwent surgery for extra iliac bone at Department of Orthopedics, the Children's Hospital, Zhejiang University School of Medicine. The present study was approved by the institutional review board of The Children's Hospital (Zhejiang, China) and written informed consent was obtained from the parents of each participant. Only children who were not taking hormones or other drugs, and had no metabolic bone disease were enrolled, comprising 2 males and 2 females, aged 3-5 years old. The obtained bone tissues were maintained aseptically, and placed in DMEM/F-12 serum-free medium (DMEM; Sigma-Aldrich, St. Louis, MO, USA) for storage at $4^{\circ} \mathrm{C}$. Bone tissues were repeatedly rinsed with $0.9 \%$ sterile saline until the rinse solution was clear without any precipitates, and were washed twice with Dulbecco's PBS. The bone tissue was cut to a size with $\sim 1 \mathrm{~mm}^{3}$ volume and digested with $0.25 \%$ trypsin at $37^{\circ} \mathrm{C}$ for $30 \mathrm{~min}$.

Bone particles were then digested 4 times using $0.1 \%$ collagenase II at $37^{\circ} \mathrm{C}$ for $30 \mathrm{~min}$. The cells were collected by centrifugation at $500 \mathrm{xg}$ for $10 \mathrm{~min}$ at $4^{\circ} \mathrm{C}$. They were inoculated into four $100 \mathrm{ml}$ flasks, DMEM/F-12 serum-free medium (DMEM; Sigma-Aldrich; Merck KGaA, Darmstadt, Germany) was added and the cells were incubated at $37^{\circ} \mathrm{C}$ in a humidified atmosphere containing $5 \% \mathrm{CO}_{2}$. According to levels of the growth, culture medium was replaced in the first 3-5 days, then it was subsequently replaced every 2-3 days. When the primary cells were grown into monolayers, the cells were digested with $0.25 \%$ trypsin for $3-5 \mathrm{~min}$ at $37^{\circ} \mathrm{C}$ to continue subculture. In addition to natural purification, enzymatic digestion and repeated adherence methods were used to purify cells (23).

Identification of osteoblasts. The isolated cells were cultured in primary culture, and morphological observation and imaging were performed under an inverted phase contrast microscope when the cells were subcultured to $80 \%$ confluence.

Cell osteocalcin immunofluorescence staining was also performed to identify osteoblasts. Osteoblasts were inoculated on coverslips and the medium was discarded when the cells reached $80 \%$ confluency; cells were then fixed with $95 \%$ ethanol for $10 \mathrm{~min}$. Cell climbing slices were washed with PBS three times for $5 \mathrm{~min}$ each, incubated at room temperature with $0.5 \%$ Triton X-100 for $10 \mathrm{~min}$, and then washed 3 times with PBS for 5 min each. Subsequently, once the slices were incubated with $5 \%$ bovine serum albumin (Sigma-Aldrich; Merck $\mathrm{KGaA}$ ) for $20 \mathrm{~min}$ at room temperature, the anti-osteocalcin antibody (ab13418; 31:100; Abcam, Cambridge, UK) was added for incubation overnight at $4{ }^{\circ} \mathrm{C}$; this was followed by 3 washes with PBS for $5 \mathrm{~min}$. The slices were then incubated with a TRITC-labeled secondary antibody (YB1130; 1:50; Dako; Agilent Technologies GmbH, Waldbronn, Germany) for $45 \mathrm{~min}$ at room temperature. Subsequently, DAPI staining was performed to stain the nuclei for $15 \mathrm{~min}$ at room temperature, which was followed by 3 washes with PBS for 5 min each. Then five fields were randomly selected from each section and observed and imaged under a laser confocal microscope.

Cell transfection. HIF-1 $\alpha$ small interfering (si)RNA (5'CCA ACCTCAGTGTGGGT-AT3') and negative siRNA control (5'CCATGTAG-GCGCAGTCTAT3') were synthesized by Shanghai GenePharma Co., Ltd. (Shanghai, China) and recombinant plasmid containing HIF-1 $\alpha$ (Addgene, Inc., Cambridge, MA, USA) were transfected into cells with Lipofectamine $2000^{\circledR}$ (Invitrogen; Thermo Fisher Scientific, Inc., Waltham, MA, USA). Briefly, prior treatment with siRNA, cells were seeded in 6-well plates and grown to $50 \%$ confluence. Transfection of $50 \mathrm{nM}$ siRNA in cells was carried out using Lipofectamine $2000^{\circledR}$ following the manufacturer's protocols. Cells were then incubated for $5 \mathrm{~h}$ at $37^{\circ} \mathrm{C}$ and the medium was replaced with complete DMEM medium (Sigma-Aldrich; Merck KGaA). Cells were harvested at least $24 \mathrm{~h}$ following transfection for use in the following experiments.

Cell viability assay. Cell viability was determined using a Cell Counting kit (CCK)-8 assay. Cells collected at 24, 
48, 72 and $96 \mathrm{~h}$ following transfection were inoculated in 96-well plates $\left(2 \times 10^{5}\right.$ cells/well) and $20 \mu \mathrm{l}$ of CCK-8 (Dojindo Molecular Technologies, Inc., Kumamoto, Japan) was added to each well. Following incubation for $4 \mathrm{~h}$ at $37^{\circ} \mathrm{C}$, the absorption was read at $450 \mathrm{~nm}$ on an ELISA reader (ELx800 ${ }^{\mathrm{TM}}$; BioTek Instruments, Minneapolis, MN, USA).

Reactive oxygen species (ROS) assay. Cells were harvested from all groups [control, negative control (NC), HIF1a, Mock and siHIF1a] and washed with PBS following transfection for $24 \mathrm{~h}$. Cells were then incubated in $20 \mu \mathrm{M} 2$ ', $7^{\prime}$-Dichorofluorescin diacetate (Sigma-Aldrich; Merck KGaA) at $37^{\circ} \mathrm{C}$ for $1 \mathrm{~h}$ following the manufacturer's protocols. Following washing with PBS, ROS levels in cells were determined using FACS Aria II flow cytometer (BD Biosciences, San Jose, CA, USA) and data analysis was performed using FlowJo version 7.6 (FlowJo LLC, Ashland, OR, USA).

Apoptosis determination by flow cytometry assay. Cells collected from all groups (control, NC, HIF1a, Mock and siHIF1a) were digested using $0.25 \%$ trypsin-EDTA for 3-5 min at $37^{\circ} \mathrm{C}$. Subsequently, cells were harvested at a density of $1 \times 10^{6}$ by centrifugation at $500 \mathrm{x}$ g for $4 \mathrm{~min}$ at $4^{\circ} \mathrm{C}$. Cells were washed with PBS and then placed in binding buffer $(140 \mathrm{mM}$ $\mathrm{NaCl}$ and $2.5 \mathrm{mM} \mathrm{CaCl} 2$ in $10 \mathrm{mM}$ HEPES/NaOH; $\mathrm{pH} 7 \cdot 4$ ). A total of $5 \mu \mathrm{l}$ propidium iodide (PI) and fluorescein isothiocyanate (FITC)-labeled Annexin V (Biodesign International; Meridian Life Science, Inc., Memphis, TN, USA) were added to cells for incubation at room temperature for $10 \mathrm{~min}$. Samples were analyzed by FACS Aria II flow cytometer (BD Biosciences) and data analysis was performed using FlowJo version 7.6 (FlowJo LLC). Those that were Annexin V-FITC positive and PI negative were considered early apoptotic cells, and late apoptotic cells were indicated by Annexin V-FITC positive and PI positive.

Western blot assay. Cells were collected from all groups and washed twice with ice-cold PBS. Cells were then lysed in radioimmunoprecipitation assay lysis buffer $(50 \mathrm{mM}$ Tris- $\mathrm{HCl}$, $200 \mathrm{mM} \mathrm{NaCl}, 1 \mathrm{mM}$ EDTA, 1 mM EGTA, 1\% Triton X-100, $0.25 \%$ deoxycholate, and protease and phosphatase inhibitors) at $37^{\circ} \mathrm{C}$ for $30 \mathrm{~min}$ and centrifuged for $20 \mathrm{~min}$ at $6,000 \mathrm{x} \mathrm{g}$ at $4^{\circ} \mathrm{C}$. The supernatants were collected and $50 \mu \mathrm{g}$ of cell lysate was used to separate proteins by $10 \%$ SDS-PAGE, which were then transferred onto a nitrocellulose membrane. The membranes were blocked with $5 \%$ non-fat dry milk for $1 \mathrm{~h}$ at room temperature. Subsequently, the blots were incubated with primary antibodies against apoptosis-inducing factor (AIF; ab32516; 1:1,000; Abcam), B-cell lymphoma 2 (Bcl-2; ab32124; 1:1,000; Abcam), Bcl-2-associated X protein (Bax; ab32503; 1:2,000; Abcam), caspase-3 (ab13585; 1:1,000; Abcam), Runx2 (ab76956; 1:1,000; Abcam), ALP (ab224335; 1:1,000; Abcam), osteocalcin (ab13420; 1:1,000; Abcam), F-actin (ab205; 1:500; Abcam) and Foxo1 (ab207204; 1:1,000; Abcam), at the appropriate dilution at $4^{\circ} \mathrm{C}$ overnight. The blots were then washed three times with TBS and incubated with horseradish peroxidase-conjugated secondary antibodies (P0260; 1:2,000 dilution; Dako; Agilent Technologies, Inc., Santa Clara, CA, USA) for at room temperature for $1 \mathrm{~h}$. The protein-antibody complexes were detected using an enhanced chemiluminescence system (GE Healthcare Life Sciences, Little Chalfont, UK). ImageJ software (version 1.42; National Institutes of Health, Bethesda, MD, USA) was used to determine densitometry.

Reverse transcription-quantitative polymerase chain reaction (RT-qPCR) assay. Cells collected from all groups were washed twice with ice-cold PBS. RNA was isolated using the RNeasy mini-kit (Qiagen GmbH, Hilden, Germany) following the manufacturer's protocols. Reverse transcription was carried out at with the iScript cDNA synthesis kit (Bio-Rad Laboratories, Inc., Hercules, CA, USA) according to the manufacturer's protocols. The temperature protocol used for RT-PCR was: $30^{\circ} \mathrm{C}$ for $10 \mathrm{~min}, 42^{\circ} \mathrm{C}$ for $30 \mathrm{~min}, 99^{\circ} \mathrm{C}$ for $5 \mathrm{~min}$ and $4^{\circ} \mathrm{C}$ for $5 \mathrm{~min}$. Subsequently, qPCR was performed using the iQ SYBR-Green Supermix (Bio-Rad Laboratories, Inc.) and iCycleriQ thermal cycler (Bio-Rad Laboratories, Inc.) following the manufacturer's protocols. The thermocycling conditions for qPCR were: $45^{\circ} \mathrm{C}$ for $10 \mathrm{~min}, 95^{\circ} \mathrm{C}$ for $10 \mathrm{~min}, 40$ cycles of $95^{\circ} \mathrm{C} 15 \mathrm{sec}$ and $60^{\circ} \mathrm{C}$ for $45 \mathrm{sec}$. Each sample was performed in duplicate. Data was calculated using the $2^{-\Delta \Delta \mathrm{Cq}}$ method (24) and relative expression was normalized to housekeeping gene (GAPDH). The primer sequences used were as follows: HIF-1 $\alpha$ forward, 5'-TCCAAGAAGCCCTAA CGTGT-3' and reverse, 5'-TGATCGTCTGGCTGCTGTAA-3'; AIF forward, 5'-TCTACCCTCTATGCCAGGACT-3' and reverse, 5'-ACCCAGATGTTAGAGCGTGC-3'; Bax forward, 5'-TCATGGGCTGGACACTGGAC-3' and reverse, 5'-CAC AGTCCAAGGCAGTGGGA-3'; Bcl-2 forward, 5'-TGGGCC ACAAGTGAAGTCAA-3' and reverse, 5'-TGATGCGGAAGT CACCGAAA-3'; caspase-3 forward, 5'-TCTGGTTTTCGG TGGGTGTG-3' and reverse, 5'-GTCGGCCTCCACTGGTA TTT-3'; Foxo1 forward, 5'-GCGCTTAGACTGTGACATGG-3' and reverse, 5'-ACTAACCCTCAGCCTGACAC-3'; Runx2 forward, 5'-CTGTGGTTACTGTCATGGCG-3' and reverse, 5'-AGGTAGCTACTTGGGGAGGA-3'; ALP forward, 5'-GTC AGTGGGAGTGGTAACCA-3' and reverse, 5'-ACATGTACT TTCGGCCTCCA-3'; Osteocalcin forward, 5'-AATCCGGAC TGTGACGAGTT-3' and reverse, 5'-TTATTTGGGAGCAGC TGGGA-3'; and GAPDH forward, 5'-CGGGAAACTGTG GCGTGATG-3', and reverse 5'-ATGACCTTGCCCACAGC CTT-3'.

Statistical analysis. All of the experimental data were expressed as the mean \pm standard deviation. A t-test was used for comparisons between two groups and a one-way analysis of variance was performed for multiple comparisons and Bonferroni post hoc test was used for pairwise comparison. All experiments were repeated at least 3 times. SPSS 22.0 software (IBM Corp., Armonk, NY, USA) was used for statistical analysis. $\mathrm{P}<0.05$ was considered to indicate a statistically significant difference.

\section{Results}

Identification of osteoblasts by morphology and fluorescence immunity. The primary cultured human osteoblasts were observed under an inverted phase contrast microscope and revealed spherical morphology prior to adherent growth. Following incubation, the cells adhered and distributed evenly on the wall of the bottle. The cells were irregularly shaped, 
A

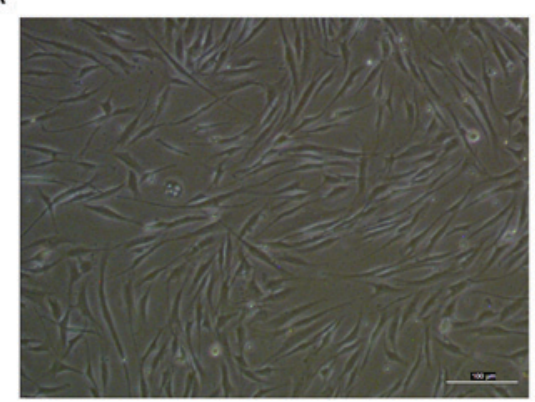

C

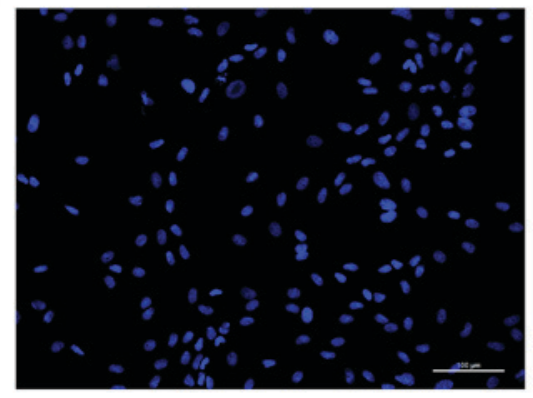

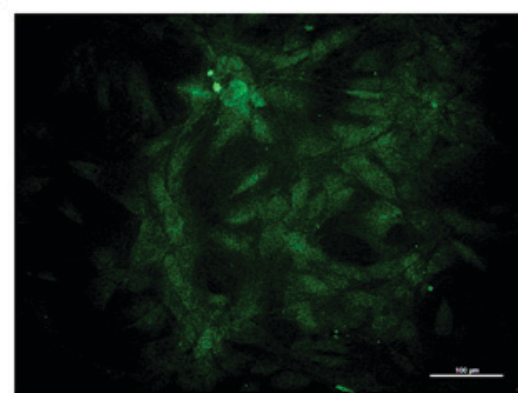

D

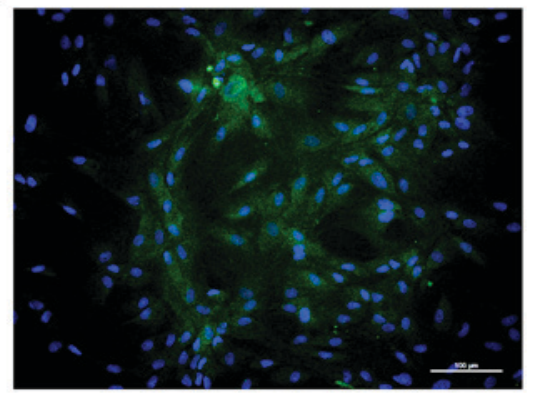

Figure 1. Osteoblasts were obtained from children's iliac cancellous bone following several purification processes. (A) The primary cultured children's osteoblasts were observed under an inverted phase contrast microscope. (B) Osteocalcin in osteoblast cytoplasm was stained in green and (C) osteocalcin in the nuclei was stained blue with DAPI; (D) these images were then merged (scale bars, $100 \mu \mathrm{m}$ ).

A

A B

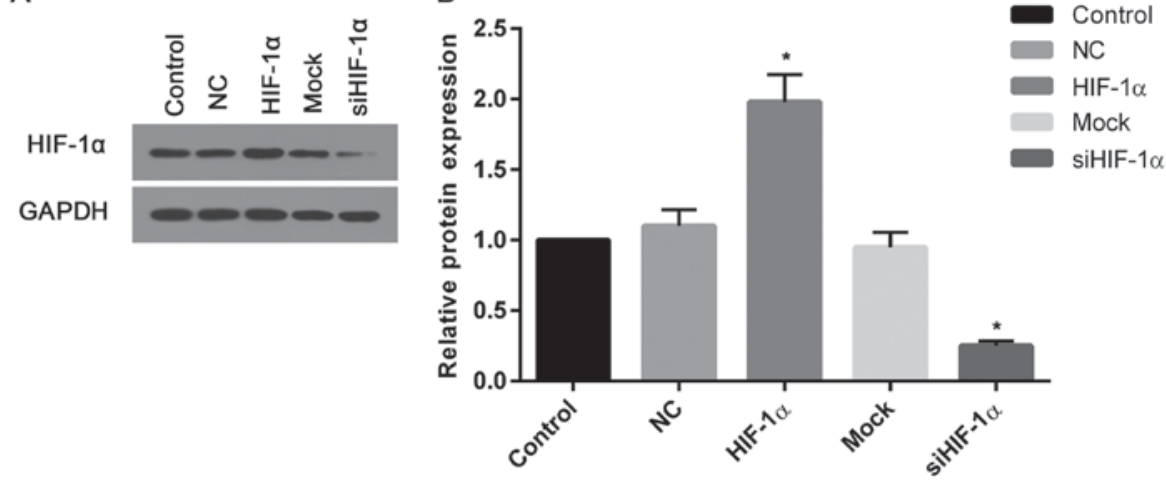

C

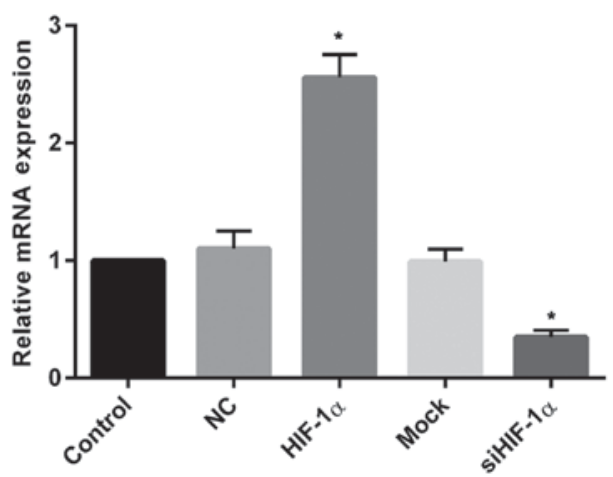

Figure 2. Western blotting and a RT-qPCR assay confirmed the transfection effectiveness. (A) Western blot analysis was performed on transfected cells and (B) revealed that HIF-1 $\alpha$ protein levels were increased in cells treated with recombinant HIF-1 $\alpha$ and decreased in cells transfected with HIF-1 $\alpha$ siRNA. (C) RT-qPCR demonstrated that HIF-1 $\alpha$ mRNA levels were significantly upregulated in cells treated with recombinant HIF-1 $\alpha$ and downregulated in cells transfected with HIF-1 $\alpha$ siRNA. "P<0.05 vs. control. RT-qPCR, reverse transcription-quantitative polymerase chain reaction; HIF-1 $\alpha$, hypoxia inducible factor-1 $\alpha$; siRNA, small interfering RNA; NC, negative control.

with long fusiform, star or irregular polygons. The cytoplasm was homogeneous and the central nucleus was round, oval centered or biased (Fig. 1A). To further confirm the osteoblasts obtained, the present study performed immunofluorescence 


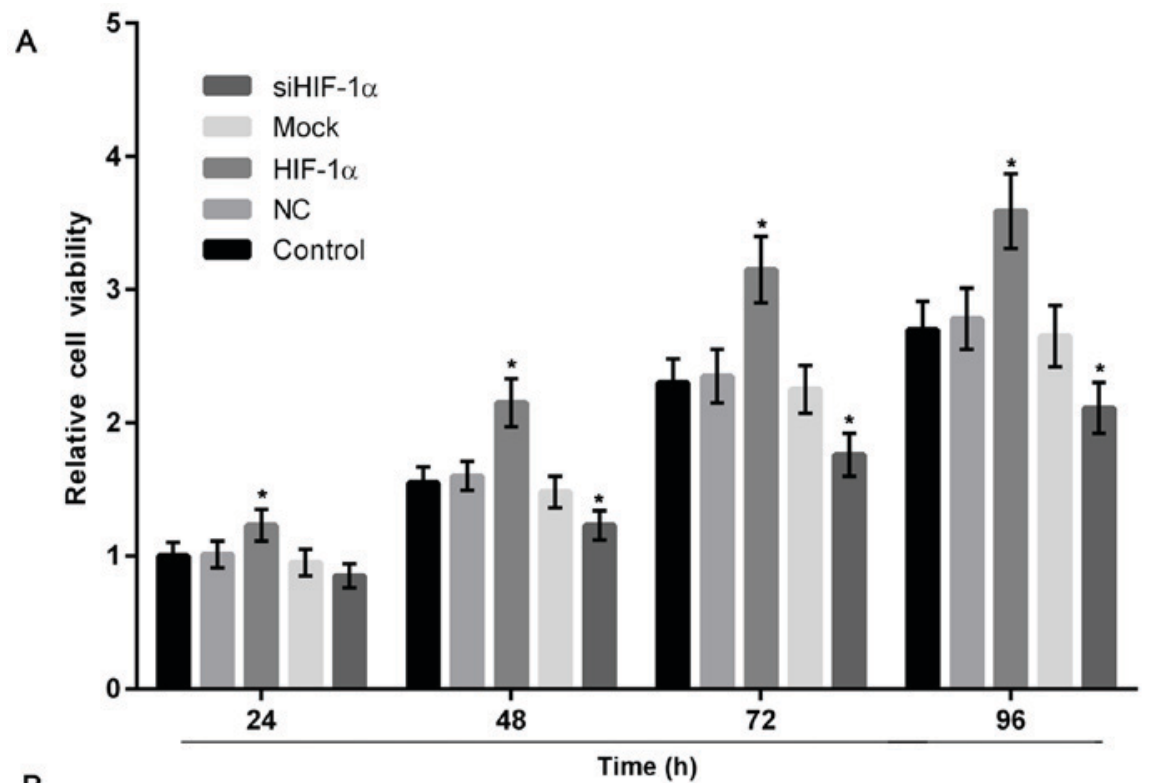

B

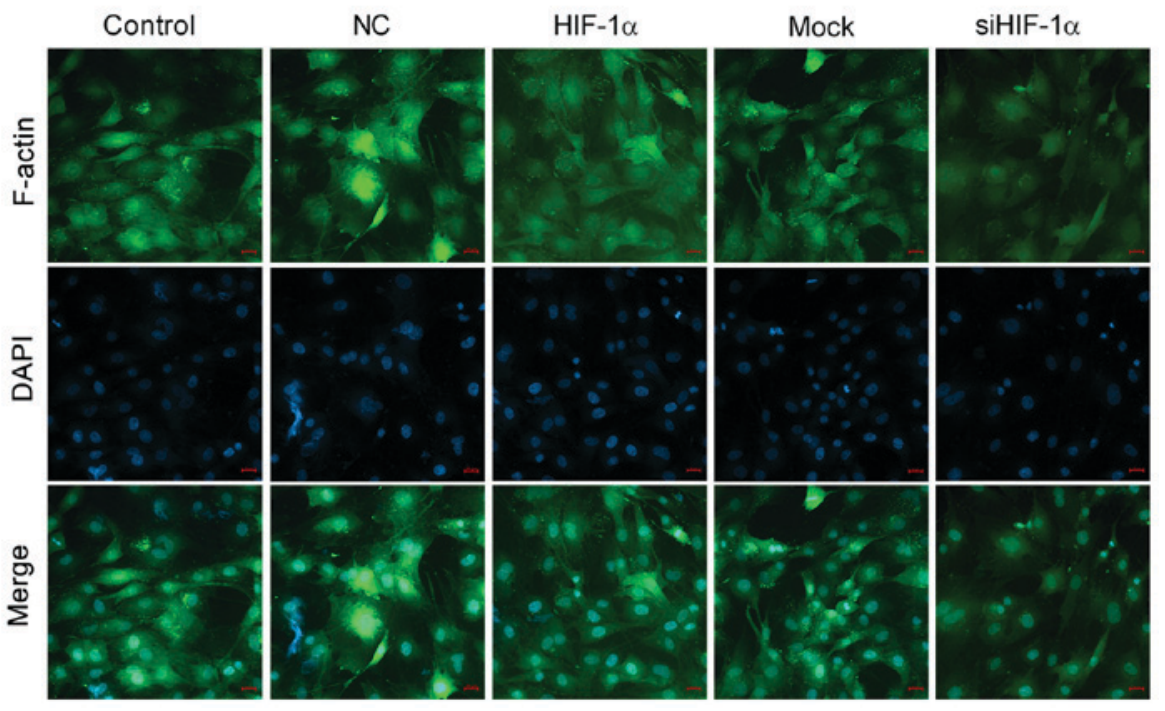

Figure 3. Altered expression of HIF-1 $\alpha$ influenced the cell viability and proliferation. (A) A Cell Counting kit-8 assay revealed that the cell viability increased in cells that overexpressed HIF-1 $\alpha$ in a time-dependent manner. By contrast, the cell viability was decreased in cells treated with HIF-1 $\alpha$ siRNA when compared with control. (B) Immunofluorescence detection of F-actin demonstrated that the expression of F-actin and osteoblast proliferation were higher in the group overexpressing HIF1 when compared with those in group with HIF1 siRNA treatment (scale bars, $20 \mu \mathrm{m}$ ). ${ }^{*} \mathrm{P}<0.05$ vs. control. HIF-1 $\alpha$, hypoxia inducible factor-1 $\alpha$; siRNA, small interfering RNA; NC, negative control.

staining of osteocalcin and osteoblasts were observed to exhibit intense cytoplasmic staining for osteocalcin (Fig. 1B-D).

Expression of HIF-1 $\alpha$ at the protein and $m R N A$ levels. To assess the transfection efficiency, the present study determined the transcriptional and translational levels of HIF-1 $\alpha$ in cells. The western blotting and mRNA assays demonstrated that the levels of HIF-1 $\alpha$ protein and mRNA in cells transfected with recombinant HIF-1 $\alpha$ were $\sim 2$ and 2.5-fold greater than that of the control (Fig. 2A and B). However, the expression of HIF- $1 \alpha$ protein and mRNA in cells treated with HIF-1 $\alpha$ siRNA were markedly suppressed when compared with the control (Fig. 2C).

HIF-1 $\alpha$ overexpression or knockdown induces or suppresses the proliferation of osteoblasts. To evaluate the effect of differentiated HIF-1 $\alpha$ expression in osteoblasts, the present study performed a CCK-8 assay, which revealed that HIF-1 $\alpha$ overexpression significantly stimulated osteoblast proliferation, while downregulation of HIF-1 $\alpha$ significantly decreased the growth of osteoblasts when compared with the control (Fig. 3A). Furthermore, in the HIF-1 $\alpha$ overexpression group, F-actin positive immunofluorescence staining was greater and osteoblast proliferation was higher, when compared with the group with HIF-1 $\alpha$ downregulation (Fig. 3B).

ROS levels increase in cells with HIF-1 $\alpha$ downregulation. To measure the levels of oxidative stress in cells up- or downregulated HIF-1 $\alpha$, the ROS levels were determined. When compared with the control and NC groups, the relative ROS level in cells treated with recombinant HIF-1 $\alpha$ was markedly reduced. By contrast, the relative ROS level in cells treated with HIF-1 $\alpha$ siRNA was elevated when compared with the control and mock groups (Fig. 4). 
A

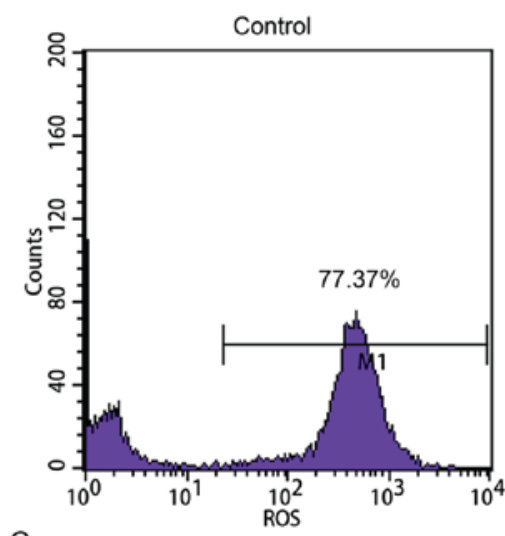

C

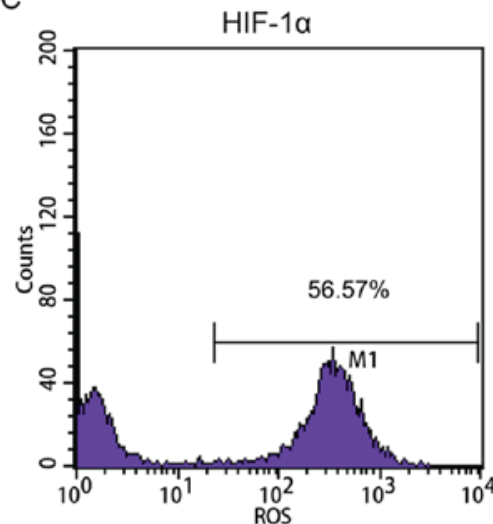

E

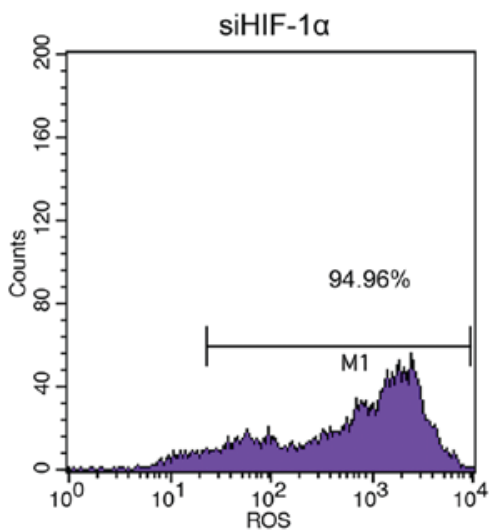

B

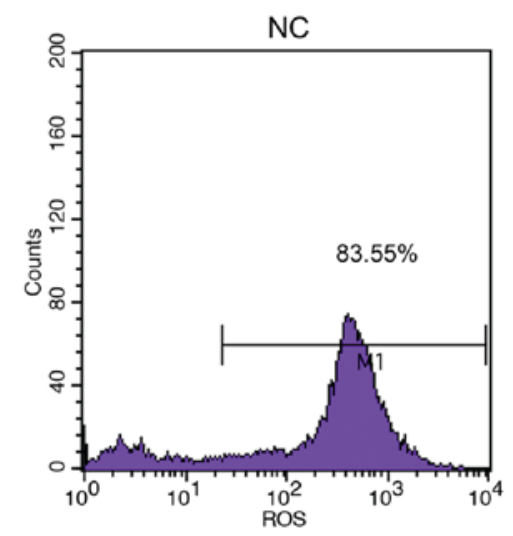

D

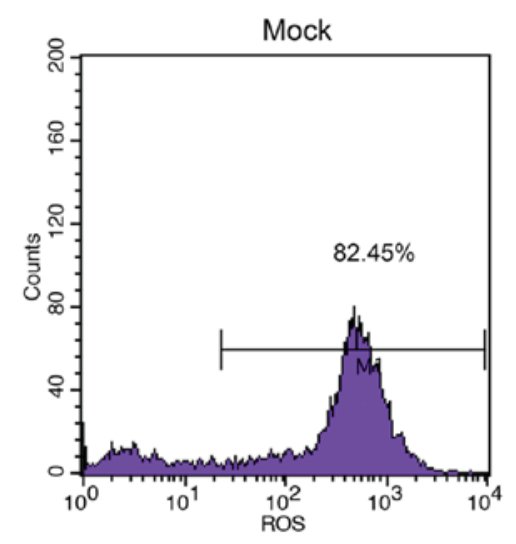

$\mathrm{F}$

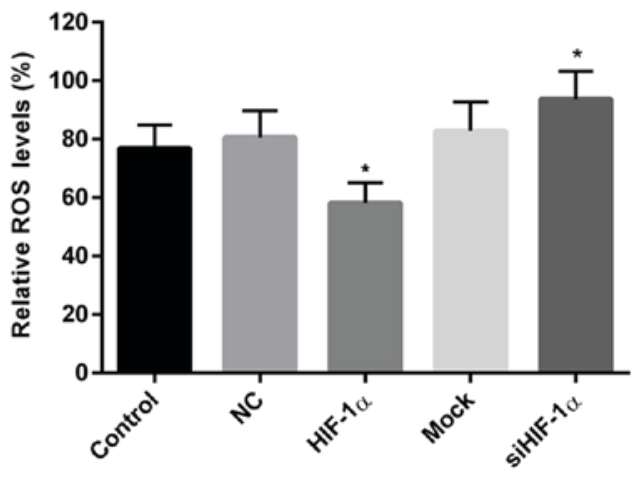

Figure 4. HIF-1 $\alpha$ overexpression and knockdown affected the ROS levels. Flow cytometry was performed on the (A) control, (B) NC, (C) recombinant HIF-1 $\alpha$, (D) Mock and (E) siHIF-1 $\alpha$ groups in order to determine (F) the relative ROS levels. The level of ROS in cells treated with recombinant HIF-1 $\alpha$ was markedly decreased when compared with the control and NC groups. However, the relative ROS level in cells with silenced HIF-1 $\alpha$ was increased when compared with the control and mock groups. "P<0.05 vs. control. HIF- $1 \alpha$, hypoxia inducible factor-1 $\alpha$; ROS, reactive oxygen species; NC, negative control; si-, small interfering RNA.

Overexpression or downregulation of HIF-1 $\alpha$ suppresses or stimulates apoptosis, respectively. The effect of overexpression or downregulation of HIF-1 $\alpha$ on apoptosis was investigated and the results revealed that the apoptosis rate of cells with HIF-1 $\alpha$ overexpression was $2.33 \%$, which was slightly lower than that of the control (3.87\%) and NC (3.93\%) groups (Fig. 5A-C and F). However, the rate of apoptosis for cells treated with HIF-1 $\alpha$ siRNA was $14.03 \%$, which was significantly higher than that of control and mock (4.32\%) groups (Fig. 5D-F).

Up-or downregulated HIF-1 $\alpha$ alters the expression of apoptosis-associated genes. To investigate the effect of HIF-1 $\alpha$ on the expression of genes associated with apoptosis, the present study further detected the expression of AIF, Bax, Bcl-2 and caspase-3. The expression levels of AIF, Bax and caspase-3 mRNA and protein decreased in cells with overexpressed HIF-1 $\alpha$, compared with the control and NC groups (Fig. 6). By contrast, they were increased in cells with downregulated HIF-1 $\alpha$, when compared with the control and mock groups. However, unlike Bax, the Bcl-2 mRNA and protein levels were increased in cells treated with recombinant HIF-1 $\alpha$ and decreased in cells treated with HIF-1 $\alpha$ siRNA when compared with the control (Fig. 6).

Overexpression or down-regulation of HIF-1 $\alpha$ increases or decreases the expression of Foxol and osteoblast markers. To 
A

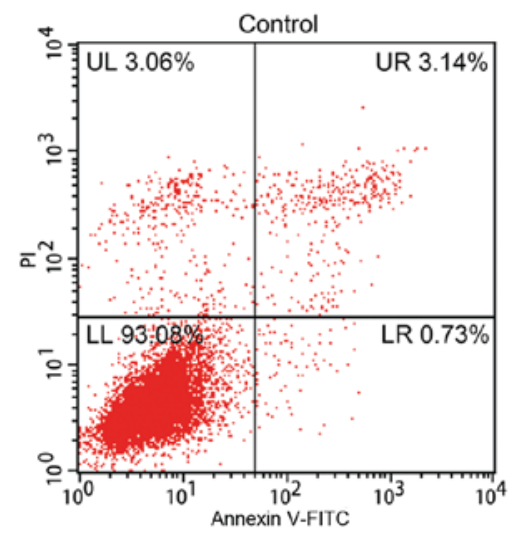

C

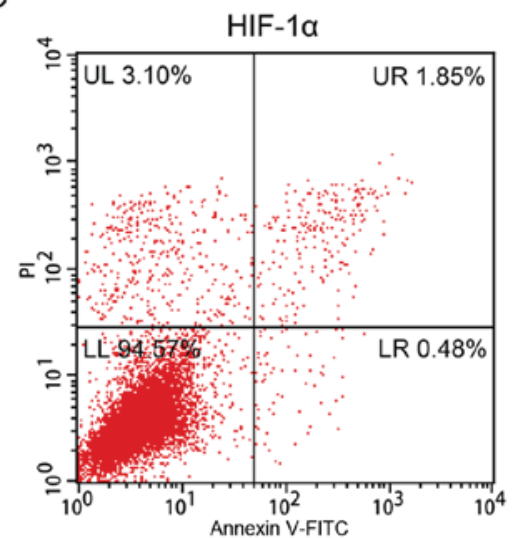

E

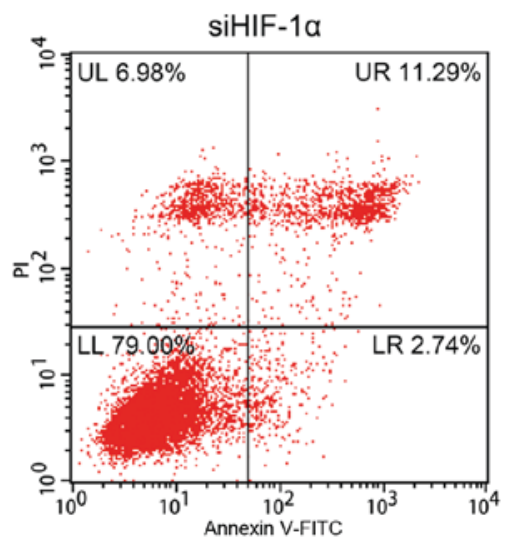

B

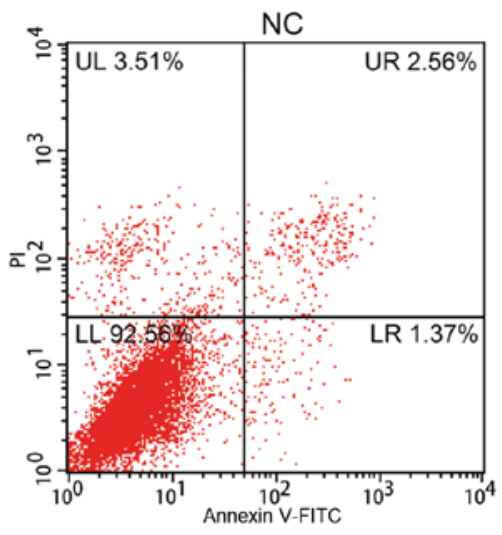

D

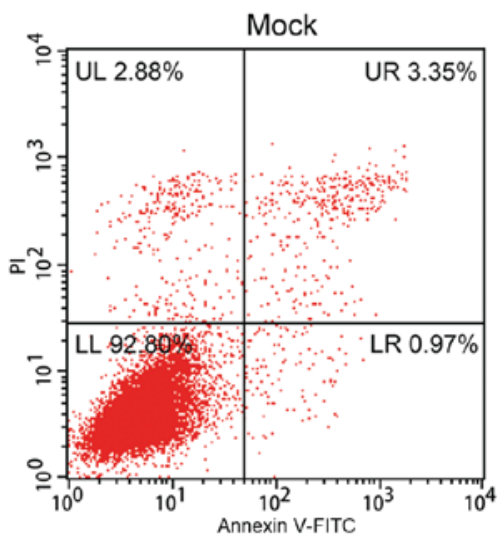

$\mathrm{F}$

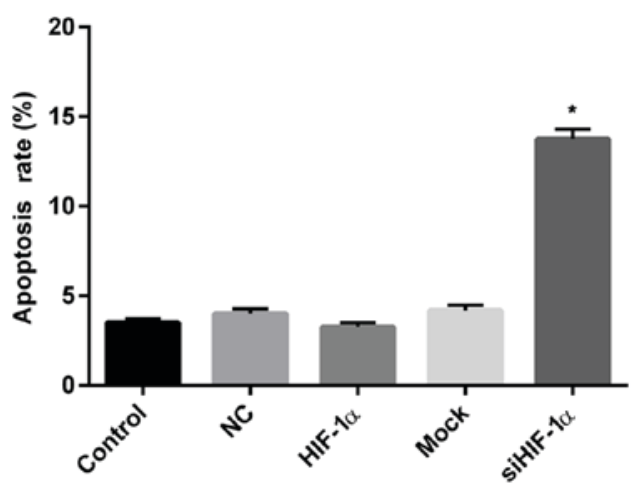

Figure 5. HIF-1 $\alpha$ overexpression and knockdown influenced osteoblast apoptosis. The rate of apoptosis in the cells of the (A) control, (B) NC, (C) recombinant HIF-1 $\alpha$, (D) Mock and (E) siHIF-1 $\alpha$ groups was evaluated. (F) HIF-1 $\alpha$ overexpression was slightly decreased when compared with the control and NC groups. By contrast, silencing HIF- $1 \alpha$ resulted in a significantly increased rate of osteoblast apoptosis. "P $<0.05$ vs. control. HIF-1 $\alpha$, hypoxia inducible factor- $1 \alpha$; NC, negative control; si-, small interfering RNA.

explore the function of HIF-1 $\alpha$ in the regulation of the expression of Foxo1 and osteoblast markers including Runx2, ALP and osteocalcin, the present study determined their expression following the upregulation or silencing of HIF-1 $\alpha$. The results demonstrated that the protein levels of Foxo1, Runx2, ALP and osteocalcin were significantly elevated in cells treated with recombinant HIF-1 $\alpha$ when compared with those of the control and NC groups (Fig. 7A and B). However, in cells treated with HIF-1 $\alpha$ siRNA, the protein levels of Foxo1, Runx2, ALP and osteocalcin were markedly decreased compared with the control and mock groups (Fig. 7A and B). Similarly, the mRNA expression levels of Foxo1, Runx2, ALP and osteocalcin in cells overexpressing HIF-1 $\alpha$ were $~ 1.5,2,2.2$ and 2.7-fold greater of that of the control and NC groups, respectively. Furthermore, the expression levels of Foxo1, Runx2, ALP and osteocalcin mRNA in cells treated with HIF-1 $\alpha$ siRNA were significantly suppressed when compared with the control and mock groups (Fig. 7C). To further confirm these altered osteoblast marker expressions, the expression of the osteogenic marker Runx2 was evaluated by immunofluorescence and the greatest Runx2 expression levels were observed in the HIF-1 $\alpha$ overexpression group, while the lowest levels were seen in cells with HIF-1 $\alpha$ silencing (Fig. 7D). In addition, to confirm the role of Foxo1 in HIF-1 $\alpha$-induced osteoblast proliferation, further blotting experiments were performed. The results revealed that Runx2 and ALP expression induced by HIF-1 $\alpha$ were markedly reversed 
A

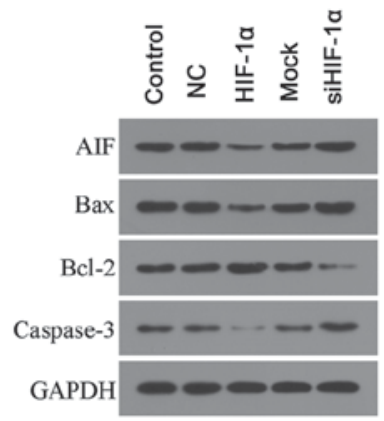

B

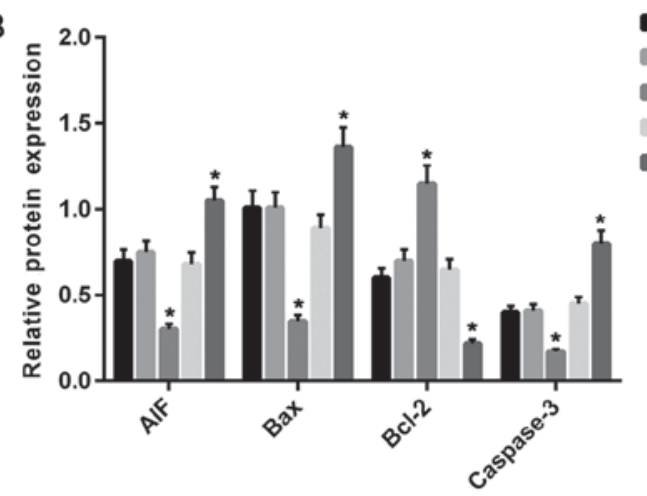

C

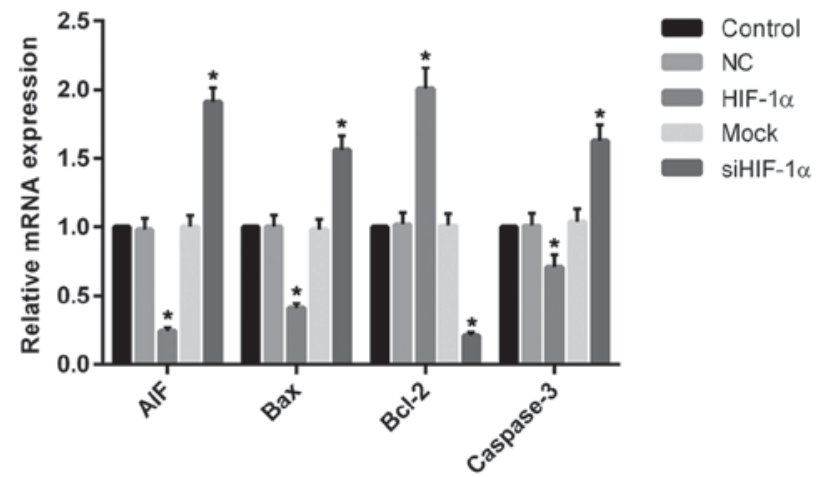

Figure 6. Expression of apoptosis associated genes was altered by the overexpression and silencing of HIF-1 $\alpha$. (A) Western blotting was performed to analyze the proteins levels of AIF, Bax, Bcl-2 and caspase-3. (B) The protein levels of AIF, Bax and caspase-3 were decreased in cells overexpressing HIF-1 $\alpha$ compared with the control and NC groups, while the level of Bcl-2 was increased when compared with control. (C) Similarly, the relative mRNA levels of AIF, Bax and caspase-3 were decreased in cells with HIF-10 overexpression compared with the control and NC groups; however, the levels of Bcl-2 mRNA were elevated when compared with control. Silencing of HIF-1 $\alpha$ had the opposite effects on protein and mRNA levels, with Bcl-2 levels significantly decreased and AIF, Bax and caspase-3 levels significantly increased. " $\mathrm{P}<0.05$ vs. control. HIF- $1 \alpha$, hypoxia inducible factor- $1 \alpha$; NC, negative control; siRNA, small interfering RNA; AIF, apoptosis-inducing factor; Bcl-2, B-cell lymphoma 2; Bax, Bcl-2-associated X protein.

by Foxol siRNA, while osteocalcin was not affected by Foxo1 siRNA (Fig. 7E). Thus, it was proposed that HIF-1 $\alpha$-induced expression of Runx 2 and ALP may be completely dependent on the expression levels of Foxo1, and in turn, osteocalcin may be partially dependent on Foxol, though to a much lesser degree.

\section{Discussion}

HIF-1 $\alpha$ serves a pivotal role in the stimulation of bone formation via the regulation of several key factors such as Runx2 (12). The Foxo subfamily regulates the expression of genes associated with a variety of physiological and pathological processes (14); however, they also have a role in the proliferation, differentiation and apoptosis of osteoblasts, which to date has been quite well studied. Previous studies have demonstrated that Foxol can stimulate the growth of osteoblasts by increasing the expression of Runx2 (17). Therefore, the present study investigated whether HIF-1 $\alpha$ affects the expression of Runx2 by regulating Foxo1. The results revealed that the interactions between HIF-1 $\alpha$ and Foxol serve a key role in the proliferation, differentiation and apoptosis of osteoblasts.

HIF- $1 \alpha$ is an important transcription factor involved in cell metabolism, with roles such as promoting glycolysis and inhibiting mitochondrial respiration (25). HIF-1 $\alpha$ upregulates pyruvate dehydrogenase kinase, inhibits pyruvate dehydrogenase activity and blocks pyruvate entry into tricarboxylic acid (TCA) cycle, thereby inhibiting mitochondrial oxidative phosphorylation (25-27). As mitochondrial respiration is the primary source of ROS, it was hypothesized that HIF-1 $\alpha$ may reduce ROS production. The results demonstrated that ROS levels were decreased in cells with overexpressed HIF-1 $\alpha$, which is consistent with the authors' hypothesis. In addition, ROS levels were markedly increased in cells treated with HIF-1 $\alpha$ siRNA compared with normal osteoblasts. These results suggested that the underlying mechanism may involve the suppression effect of HIF-1 $\alpha$ on ROS in osteoblasts.

In the process of bone development and regeneration, angiogenesis is closely associated with bone neoplasm (28). Previous studies had observed that HIF-1 $\alpha$ can promote the proliferation and migration of vascular endothelial cells, and increase the permeability of vascular endothelial cells $(29,30)$, which provides nutrition for the growth of cells and the establishment of capillaries, and also promotes the development of bone marrow-derived endothelial progenitor cells that transfer to the site of hypoxic injury $(30,31)$. Thus, the present study measured the cell viabilities and rates of apoptosis in osteoblasts with HIF-1 $\alpha$ overexpression or knockdown. The results revealed that the cell viabilities and proliferation were increased in cells with overexpression, and decreased in cells with downregulated HIF-1 $\alpha$. Furthermore, apoptosis was significantly increased in cells with silenced HIF-1 $\alpha$; however, the apoptosis rate in cells with overexpressed HIF-1 $\alpha$ was marginally decreased compared with normal cells. Consistent with these results, the expression levels of the proapoptotic genes AIF, Bax and caspase-3 were increased, while the anti-apoptotic gene $\mathrm{Bcl}-2$ was decreased in cells treated with HIF-1 $\alpha$ siRNA. These results and those of previous reports indicate that the inhibition of HIF-1 $\alpha$ function suppresses osteoblast proliferation (12).

The Foxo family mainly includes Foxo1, Foxo3 and Foxo4, and is a group comprised of multifunctional transcription factors involved in the cell cycle, apoptosis and ROS metabolism (14). In addition, previous investigations revealed that Foxol is closely associated with the proliferation, differentiation and apoptosis of osteoblasts $(16,18,32,33)$. Therefore, the present study detected the expression levels of Foxol in order to determine the associations between HIF- $1 \alpha$ and Foxol. The transcriptional and translational levels of Foxol were increased in cells with HIF-1 $\alpha$ overexpression. Previous studies have demonstrated that Foxol can upregulate the ROS reducing agent manganese peroxidase, Catalase and sestrin 3 , which produce superoxide oxidation, antioxidant protein (overoxidized peroxiredoxins) 


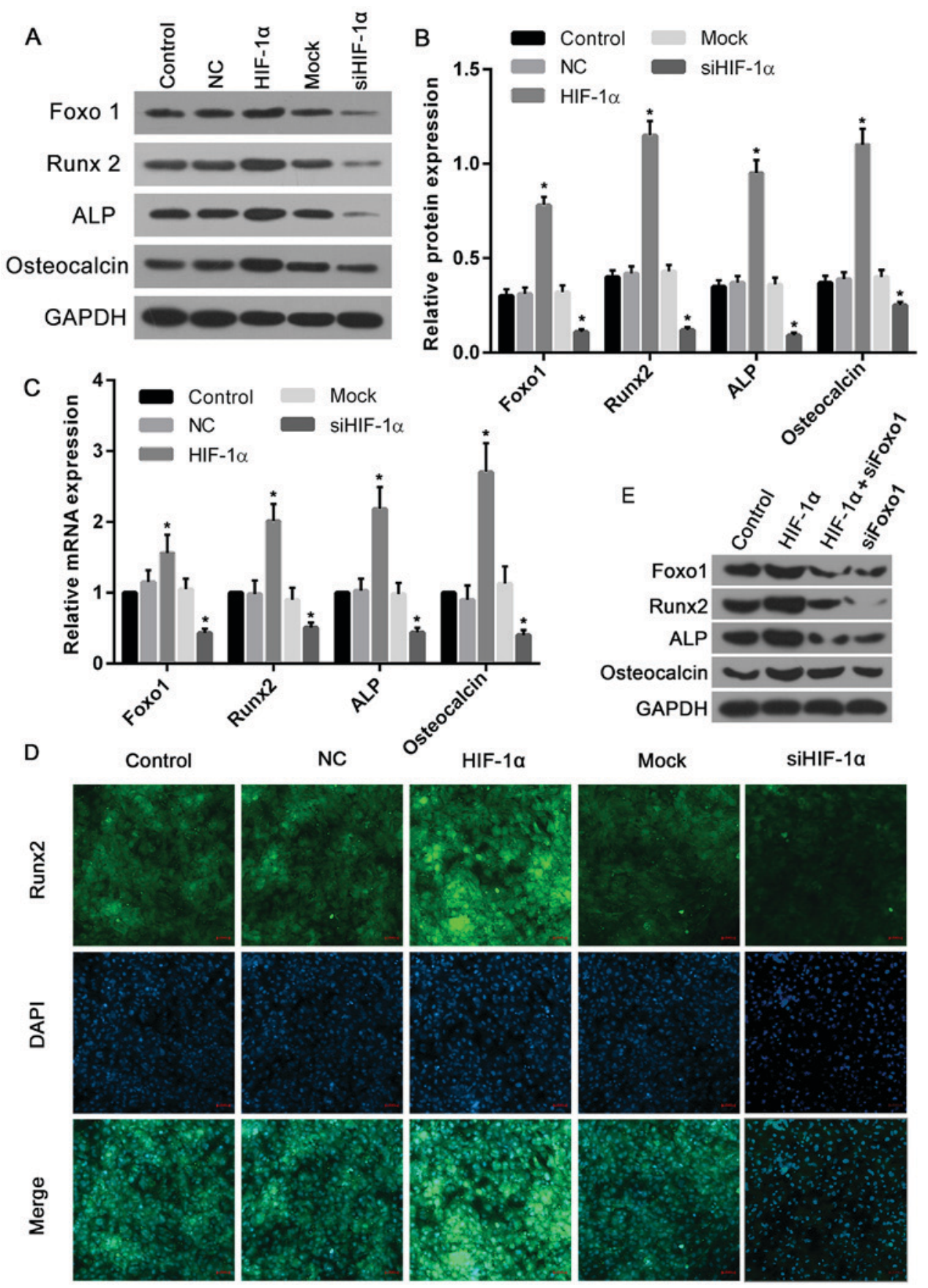

Figure 7. HIF-1 $\alpha$ overexpression increased, and knockdown decreased, the expression levels of Foxol and osteoblast markers. (A) Western blotting was performed to analyze the proteins levels of Foxo1, Runx2, ALP and osteocalcin. (B) Their protein expression levels significantly increased in cells overexpressing HIF-1 $\alpha$ when compared with the control and NC groups. However, the protein levels significantly decreased in cells treated with HIF-1 $\alpha$ siRNA, compared with the control and mock groups. (C) Similarly, the mRNA expression levels of Foxo, Runx2, ALP and osteocalcin in cells with HIF-1 $\alpha$ overexpression were elevated, while the mRNA levels in cells treated with HIF-1 $\alpha$ siRNA were significantly inhibited. (D) Immunofluorescence analysis confirmed that the highest expression of Runx2 was observed in cells overexpressing HIF-1 $\alpha$, while the lowest expression of Runx2 was exhibited by cells with HIF-1 $\alpha$ silencing (scale bars, $50 \mu \mathrm{m}$ ). (E) Runx2 and ALP protein expression induced by HIF1 $\alpha$ were markedly decreased by Foxol siRNA, while only a slight reduction in osteocalcin was produced by Foxol siRNA. " $\mathrm{P}<0.05$ vs. control. HIF-1 $\alpha$, hypoxia inducible factor- $1 \alpha$; NC, negative control; si-/siRNA, small interfering RNA; Runx2, runt-related transcription factor 2; ALP, alkaline phosphatase; Foxo1, forkhead box class O1.

degradation of ROS $(34,35)$. Therefore, it was assumed in the present study that the increased ROS levels in cells with HIF-1 $\alpha$ silencing were associated with the downregulation of Foxo1 induced by knockdown HIF-1 $\alpha$. Notably, the complete knockdown of Foxol in vivo has previously been observed to induce the incomplete development of the embryonic vascular system, which in turn leads to the apoptosis of embryonic cells and thus, the termination of the pregnancy (36). Furthermore,
Foxol serves a pivotal protective role in endoplasmic reticulum stress-, hypoxia- and tumor necrosis factor-induced apoptosis in a variety of cell lines (37-39). Therefore, the interactions between HIF-1 $\alpha$ and Foxol may be an important factor for the regulation of osteoblast apoptosis.

To date, HIF-1 has been associated with the regulation of a variety of genes including VEGF, bone morphogenetic protein and osteocalcin, which in turn are closely associated 
with angiogenesis and bone formation (30,31). Several studies have reported that the deletion of HIF-1 $\alpha$ results in the downregulation of osteoblast markers, including Runx2, ALP and osteocalcin $(12,40,41)$. However, the mechanism by which HIF-1 $\alpha$ regulates these genes remains unclear. In addition, a number of investigations have revealed that knockout of Foxo1 markedly reduced the expression of Runx2, ALP and osteocalcin, resulting in the reduction of culture calcification even with exposure to osteogenic stimulants $(17,19,32)$. Thus, it was hypothesized in the present study that there may be a close association between HIF-1 $\alpha$ and Foxol in the regulation of the expression of these genes. Therefore, the expression of these genes was further investigated. The results revealed that Runx 2 and ALP expression induced by HIF1 $\alpha$ were markedly reduced by Foxo1 siRNA; however, osteocalcin was not notably affected by Foxol siRNA. It is therefore a possibility that the HIF1 $\alpha$-induced expression of Runx 2 and ALP may be completely dependent upon the expression levels of Foxo1, and osteocalcin may be partially dependent on Foxo1. The results of the present study were consistent with the authors' hypothesis and with the results of previous studies $(17,18,32)$. Notably, the mRNA and protein levels of Runx2, ALP and osteocalcin had similar expression profiles as those of HIF-1 $\alpha$ and Foxol. Silencing HIF-1 $\alpha$ resulted in the decreased expression of Runx2, ALP and osteocalcin, while overexpression of HIF-1 $\alpha$ led to an increased expression of Runx2, ALP and osteocalcin. The accumulation of HIF-1 $\alpha$ protein has been associated with Runx 2 in ATDC5 chondrocytes and HEK293 cells (42). In addition, Runx 2 can promote the nuclear translocation of HIF-1 $\alpha$ in HEK293 cells (42). Runx2 can also stabilize the structure of HIF-1 $\alpha$ by suppressing the ubiquitination of HIF-1 $\alpha(40,42)$. In fact, there are only two specific transcripts in osteoblasts, one encoding Runx 2 and the other encoding osteocalcin, in which osteocalcin is an inhibitor of osteoclast function and is expressed only when osteoblasts are completely differentiated $(43,44)$. Furthermore, Runx 2 is required for the expression of osteoblast-specific proteins such as osteocalcin (44). Through the regulation of osteocalcin expression, Runx 2 can promote bone formation in differentiated osteoblasts (45).

In conclusion, the results of the present study indicated that the dependent activation of Foxol by HIF-1 $\alpha$ may be essential for osteoblast cell survival, differentiation and proliferation. The increased viabilities of osteoblasts derived from children's iliac cancellous bone with elevated HIF-1 $\alpha$ and Foxol levels provides evidence for novel approaches that stimulate the development of osteoblasts by activating HIF-1 $\alpha$ and Foxo1 in combination.

\section{Acknowledgements}

Not applicable.

\section{Funding}

No funding was received.

\section{Availability of data and materials}

All data generated or analyzed during this study are included in this published article.

\section{Authors' contributions}

GX performed the experiments and wrote and revised the manuscript.

\section{Ethics approval and consent to participate}

The present study was approved by the institutional review board of The Children's Hospital (Zhejiang, China).

\section{Consent for publication}

Written informed consent was obtained from the parents of each participant.

\section{Competing interests}

The author declares that he has no competing interests.

\section{References}

1. Moradi R and Atik OS: Are orthopedic surgeons more aware of medical treatment of osteoporotic fractures in the last decade? Eklem Hastalik Cerrahisi 25: 80-84, 2014 (In Turkish).

2. Zheng L, Kelly CJ and Colgan SP: Physiologic hypoxia and oxygen homeostasis in the healthy intestine. A review in the theme: Cellular responses to hypoxia. Am J Physiol Cell Physiol 309: C350-C360, 2015.

3. Iranon NN and Miller DL: Interactions between oxygen homeostasis, food availability, and hydrogen sulfide signaling. Front Genet 3: 257, 2012.

4. Atkinson PJ, Cooper TG, Anseth S, Walter NE, Kargus R and Haut RC: Association of knee bone bruise frequency with time postinjury and type of soft tissue injury. Orthopedics 31: 440 2008.

5. Murata K, Ito H, Yoshitomi H, Yamamoto K, Fukuda A, Yoshikawa J, Furu M, Ishikawa M, Shibuya H and Matsuda S: Inhibition of miR-92a enhances fracture healing via promoting angiogenesis in a model of stabilized fracture in young mice. J Bone Miner Res 29: 316-326, 2014.

6. Fauzi A, Kamal AF, Kurniawan A and Kodrat E: Role of sildenafil in acceleration of delayed union fracture healing on Sprague-Dawley rats model. Br J Med Med Res 8: 419-428, 2015.

7. Fang TD, Salim A, Xia W, Nacamuli RP, Guccione S, Song HM Carano RA, Filvaroff EH, Bednarski MD, Giaccia AJ and Longaker MT: Angiogenesis is required for successful bone induction during distraction osteogenesis. J Bone Miner Res 20: 1114-1124, 2005

8. Molica S, Vitelli G, Levato D, Gandolfo GM and Liso V: Increased serum levels of vascular endothelial growth factor predict risk of progression in early B-cell chronic lymphocytic leukaemia. Br J Haematol 107: 605-610, 1999.

9. Benita Y, Kikuchi H, Smith AD, Zhang MQ, Chung DC and Xavier RJ: An integrative genomics approach identifies Hypoxia inducible factor-1 (HIF-1)-target genes that form the core response to hypoxia. Nucleic Acids Res 37: 4587-4602, 2009.

10. Chen D, Tian W, Li Y, Tang W and Zhang C: Osteoblast-specific transcription factor Osterix (Osx) and HIF-1 $\alpha$ cooperatively regulate gene expression of vascular endothelial growth factor (VEGF). Biochem Biophys Res Commun 424: 176-181, 2012.

11. Lechler P, Klein SM, Prantl L, Englert C, Renkawitz T and Grifka J: Hypoxic downregulation of cellular proliferation and loss of phenotype stability in human osteoblasts is mediated by HIF-1 $\alpha$. Clin Hemorheol Microcirc 49: 279-286, 2011.

12. Lin L, Shen Q, Leng H, Duan X, Fu X and Yu C: Synergistic inhibition of endochondral bone formation by silencing Hif $1 \alpha$ and Runx 2 in trauma-induced heterotopic ossification. Mol Ther 19: 1426-1432, 2011.

13. Kim HS, Nam JS, Le SS, Kim LS, Ryu BY, Kang HJ, Choi BS, Ganbold B and Ko YC: Abstract 564: Foxo3a regulates cell cycle arrest through the regulation of p53, p21 and GADD45 signaling activity in Quercetin-treated MDA-MB-231 breast cancer cells. Cancer Res 73: 564, 2013. 
14. Lu $\mathrm{H}$ and Huang $\mathrm{H}$ : FOXO1: A potential target for human diseases. Curr Drug Targets 12: 1235-1244, 2011.

15. Brown J, Wang H, Suttles J, Graves DT and Martin M: Mammalian target of rapamycin complex 2 (mTORC2) negatively regulates toll-like receptor 4-mediated inflammatory response via FoxO1. J Biol Chem 286: 44295-44305, 2011.

16. Kim KM, Park SJ, Jung SH, Kim EJ, Jogeswar G, Ajita J, Rhee Y, Kim CH and Lim SK: miR-182 is a negative regulator of osteoblast proliferation, differentiation, and skeletogenesis through targeting FoxO1. J Bone Miner Res 27: 1669-1679, 2012.

17. Yang S, Xu H, Yu S, Cao H, Fan J, Ge C, Fransceschi RT, Dong HH and Xiao G: Foxol mediates insulin-like growth factor 1 (IGF1)/insulin regulation of osteocalcin expression by antagonizing Runx2 in osteoblasts. J Biol Chem 286: 19149-19158, 2011

18. Teixeira CC, Liu Y, Thant LM, Pang J, Palmer G and Alikhani M Foxo1, a novel regulator of osteoblast differentiation and skeletogenesis. J Biol Chem 285: 31055-31065, 2010.

19. Kubat O, Šmigovec I, Đapić T and Antičević D: Cystic-like lesions of proximal femur associated with fractures in children and adolescents-diagnostic and therapeutic dilemma. J, 2012

20. Madadi F, Shamsian BS, Alavi S, Madadi F, Eajazi A and Aslani A: Avascular necrosis of the femoral head in children with acute lymphoblastic leukemia: A 4- to 9-year follow-up study. Orthopedics 34: e593-e597, 2011

21. Canale ST: Fracture of hip in children and adolescents. Orthop Clin North Am 21: 341-352, 1990

22. Karatoprak O, Korkmaz MF, Kara AN, Göğüş A and Işiklar ZU: Early results of autologous mononuclear bone marrow cell implantation in nontraumatic avascular necrosis of the femoral head. Acta Orthop Traumatol Turc 42: 178-183, 2008

23. Siggelkow H, Rebenstorff K, Kurre W, Niedhart C, Engel I, Schulz H, Atkinson MJ and Hüfner M: Development of the osteoblast phenotype in primary human osteoblasts in culture: Comparison with rat calvarial cells in osteoblast differentiation. J Cell Biochem 75: 22-35, 1999.

24. Livak KJ and Schmittgen TD: Analysis of relative gene expression data using real-time quantitative PCR and the 2(-Delta Delta C(T)) method. Methods 25: 402-408, 2001.

25. Bel Aiba RS, Dimova EY, Görlach A and Kietzmann T: The role of hypoxia inducible factor-1 in cell metabolism-a possible target in cancer therapy. Expert Opin Ther Targets 10: 583-599, 2006.

26. Sudarshan S, Sourbier C, Kong HS, Block K, Valera Romero VA, Yang Y, Galindo C, Mollapour M, Scroggins B, Goode N, et al: Fumarate hydratase deficiency in renal cancer induces glycolytic addiction and hypoxia-inducible transcription factor 1alpha stabilization by glucose-dependent generation of reactive oxygen species. Mol Cell Biol 29: 4080-4090, 2009.

27. Lu CW, Lin SC, Chen KF, Lai YY and Tsai SJ: Induction of pyruvate dehydrogenase kinase-3 by hypoxia-inducible factor-1 promotes metabolic switch and drug resistance. J Biol Chem 283: 28106-28114, 2008

28. Dai J and Rabie AB: VEGF: An essential mediator of both angiogenesis and endochondral ossification. J Dent Res 86: 937-950, 2007.

29. Kim CH, Kin JK and Yoon JH: Dendritic epidermal T cells promote wound healing by production of vascular endothelial growth factor mediated by HIF-1a signaling. Am J Respir Crit Care Med 185: A4272, 2012

30. Kiani AA, Kazemi A, Halabian R, Mohammadipour M, Jahanian-Najafabadi A and Roudkenar MH: HIF-1 $\alpha$ confers resistance to induced stress in bone marrow-derived mesenchymal stem cells. Arch Med Res 44: 185-193, 2013
31. Jiang C, Sun J, Dai Y, Cao P, Zhang L, Peng S, Zhou Y, Li G, Tang $\mathrm{J}$ and Xiang J: HIF-1A and C/EBPs transcriptionally regulate adipogenic differentiation of bone marrow-derived MSCs in hypoxia. Stem Cell Res Ther 6: 21, 2015.

32. Siqueira MF, Flowers S, Bhattacharya R, Faibish D, Behl Y, Kotton DN, Gerstenfeld L, Moran E and Graves DT: FOXO1 modulates osteoblast differentiation. Bone 48: 1043-1051, 2011.

33. Moriishi T, Kawai Y, Komori H, Rokutanda S, Eguchi Y, Tsujimoto Y, Asahina I and Komori T: Bcl2 deficiency activates FoxO through Akt inactivation and accelerates osteoblast differentiation. PLoS One 9: e86629, 2014.

34. Alikhani M, Maclellan CM, Raptis M, Vora S, Trackman PC and Graves DT: Advanced glycation end products induce apoptosis in fibroblasts through activation of ROS, MAP kinases, and the FOXO1 transcription factor. Am J Physiol Cell Physiol 292: C850-C856, 2007.

35. Chen CC, Jeon SM, Bhaskar PT, Nogueira V, Sundararajan D, Tonic I, Park Y and Hay N: FoxOs inhibit mTORC1 and activate Akt by inducing the expression of sestrin3 and rictor. Dev Cell 18: 592-604, 2010.

36. Hosaka T, Biggs WH III, Tieu D, Boyer AD, Varki NM, Cavenee WK and Arden KC: Disruption of forkhead transcription factor (FOXO) family members in mice reveals their functional diversification. Proc Natl Acad Sci USA 101: 2975-2980, 2004.

37. Shen B, Chao L and Chao J: Pivotal role of JNK-dependent FOXO1 activation in downregulation of kallistatin expression by oxidative stress. Am J Physiol Heart Circ Physiol 298: H1048-H1054, 2010.

38. Martinez S, Tanabe KM, Cras-Méneur C, Abumrad NA, Bernal-Mizrachi E and Permutt M: Inhibition of Foxol protects pancreatic islet beta-cells against fatty acid and endoplasmic reticulum stress-induced apoptosis. Diabetes 57: 846-859, 2008.

39. Alikhani M, Alikhani Z and Graves DT: FOXO1 functions as a master switch that regulates gene expression necessary for tumor necrosis factor-induced fibroblast apoptosis. J Biol Chem 280: 12096-12102, 2005.

40. Kwon TG,Zhao X, Yang Q,Li Y, Ge C,Zhao G and Franceschi RT: Physical and functional interactions between Runx2 and HIF-1a induce vascular endothelial growth factor gene expression. J Cell Biochem 112: 3582-3593, 2011.

41. Hirata M, Kugimiya F, Fukai A, Saito T, Yano F, Ikeda T, Mabuchi A, Sapkota BR, Akune T, Nishida N, et al: C/EBP $\beta$ and RUNX2 cooperate to degrade cartilage with MMP-13 as the target and HIF-2 $\alpha$ as the inducer in chondrocytes. Hum Mol Genet 21: 1111-1123, 2012.

42. Lee SH, Che X, Jeong JH, Choi JY, Lee YJ, Lee YH, Bae SC and Lee YM: Runx2 protein stabilizes hypoxia-inducible factor-1 $\alpha$ through competition with von Hippel-Lindau protein (pVHL) and stimulates angiogenesis in growth plate hypertrophic chondrocytes. J Biol Chem 287: 14760-14771, 2012

43. Sierra J, Villagra A, Paredes R, Cruzat F, Gutierrez S, Javed A, Arriagada G, Olate J, Imschenetzky M, Van Wijnen AJ, et al: Regulation of the bone-specific osteocalcin gene by p300 requires Runx2/Cbfa1 and the vitamin D3 receptor but not p300 intrinsic histone acetyltransferase activity. Mol Cell Biol 23 3339-3351, 2003

44. Xiao G, Jiang D, Ge C, Zhao Z, Lai Y, Boules H, Phimphilai M, Yang X, Karsenty G and Franceschi RT: Cooperative interactions between activating transcription factor 4 and Runx $2 / \mathrm{Cbfa} 1$ stimulate osteoblast-specific osteocalcin gene expression. J Biol Chem 280: 30689-30696, 2005.

45. Komori T: Regulation of osteoblast differentiation by Runx2. Adv Exp Med Biol 658: 43-49, 2010 